\title{
Regionalization of Precipitation Regimes in Iran Using Principal Component Analysis and Hierarchical Clustering Analysis
}

\author{
Mohammad Darand • \\ Mohammad Reza Mansouri Daneshvar
}

Received: 14 August 2014 / Accepted: 1 October 2014 / Published online: 14 October 2014

(C) Springer International Publishing Switzerland 2014

\begin{abstract}
Daily gridded precipitation data, between years 1951 and 2007, obtained from APHRODITE database, were analyzed to regionalize precipitation regimes in Iran country. The S-mode of principal component analysis (PCA) was applied on seasonal correlation matrix with eight derived variables. Based on eigenvalues over one, three factors were extracted between the components and varimax rotation was used to enhance interpretability of retained PCA scores. Then, hierarchical clustering analysis (HCA) was applied to group the homogeneous precipitation regimes. According to the HCA, nine distinct and homogenous regions were recognized. Then, the Kolmogorov-Smirnov test on seasonal percentage of precipitation distribution in these regions was used to identify the independent regimes which have been spatially mapped by using GIS. This study showed that the APHRODITE dataset potentially could be used for regionalization of precipitation regimes in Iran. According to the results, use of this dataset in order to group precipitation regimes is recommended for arid and semi-arid regions of mid-latitudes, especially in the Middle East countries.
\end{abstract}

Keywords Precipitation Regimes · Principal Component Analysis (PCA) · Hierarchical Clustering Analysis (HCA) · GIS · Iran

\section{Introduction}

Precipitation is one of the most important climate elements that directly affect the availability of water resources (Randall et al. 2007). Also, regionalization of precipitation regime is essential for the optimum design and management of water related activities. Spatial distribution and temporal trend of precipitation have been widely studied in some regions, such as in the Mediterranean areas (Rodrigo and Trigo 2007; Martínez et al. 2007; Longobardi and Villani 2009; Beguería et al. 2009; Mourato et al. 2010; López-Moreno et al. 2010), in Iran

M. Darand

Department of Climatology, University of Kurdistan, Sanandaj, Iran

M. R. Mansouri Daneshvar $(\bowtie)$

Department of Geography, Mashhad Branch, Islamic Azad University, Mashhad, Iran

e-mail: mrm_daneshvar2012@yahoo.com 
(Modarres and Sarhadi 2009; Tabari and Hosseinzadeh Talaee 2011; Raziei et al. 2012, 2014; Soltani et al. 2012; Dinpashoh et al. 2014), in India (Guhathakurta and Rajeevan 2008; Jain and Kumar 2012; Dimri and Dash 2012; Jhajharia et al. 2012) and in Africa (Cheung et al. 2008; Senapathi et al. 2010; Kassile 2013). Likewise, precipitation regimes have been studied in different regions such as Sri Lanka (Puvaneswaran and Smithson 1993), southwest United States and northern Mexico (Comrie and Glenn 1998), Nepal (Kansakar et al. 2004) and China (Chen et al. 2009; Xiao et al. 2013).

There are several methods for assessing climate regionalization, including principal component analysis (PCA), hierarchical clustering analysis (HCA), empirical orthogonal function (EOF), and simple correlation analysis (Chen et al. 2009). The purpose of PCA is to identify the most important correlation structures between a number of variables in order to obtain a description of the major part of the overall variance with few linear combinations based on the original variables (Muñoz-Díaz and Rodrigo 2004). Arriaga-Ramírez and Cavazos (2010) applied the rotated PCA on the monthly precipitation S-mode data (multiple stations over time) to produce precipitation regions in northwest Mexico and the southwest United States. The retained PC scores corresponding to $\mathrm{R}$-mode (multiple times over station) or S-mode are compounded. PCAs can be subjected to cluster analysis (CA) to better identify different subregions (e.g., Marzban and Sandgathe 2006). The CA technique, similarly to PCA method, is known for its ability to divide the dataset into homogeneous and distinct groups, having members with similar characteristics (Shukla et al. 2000). The CA is one of the most useful tasks in the data mining process for discovering groups and identifying interesting patterns in the underlying data (Halkidi et al. 2001). Some significant applications of PCA in climate research include those by Yu et al. (1997), Monahan (2000), Hsieh (2001), Cannon et al. (2002), Camberlin and Diop (2003), Giannini et al. (2003), Astel et al. (2004), Muñoz-Díaz and Rodrigo (2004) and Jhajharia et al. (2013).

There are hierarchical and non-hierarchical methods for cluster analysis. Hierarchical methods are based on a distance matrix. Euclidean distance is the most commonly used measure, although many other distance measures exist (Gong and Richman 1995). In Iran, Domroes et al. (1998) have used PCA and HCA for mean monthly precipitation estimation based on 71 stations, resulting in five homogeneous precipitation regions. Dinpashoh et al. (2004) have regionalized Iran's precipitation climate using multivariate methods resulting in six homogeneous precipitation regions. Soltani et al. (2007) have used monthly precipitation time series from 28 main sites to determine regional rainfall climates of Iran. A hierarchical cluster analysis was applied to the autocorrelation coefficients at different lags, and three main rainfall climatic groups were found. Raziei et al. (2008) applied PCA on the nine seasonal and annual precipitation-derived parameters of 140 stations in western Iran, covering the period 1965-2000. Applying the CA to the four varimax rotated PC scores suggested that five spatially homogenous sub-regions exist, characterized by different precipitation regimes.

All these studies have used station-based data to regionalization of precipitation regimes without any gridded datasets. Understanding spatial variation in climatic conditions is a key to many agricultural, hydrological, natural and water resources management studies. However, meteorological and climatic variables are usually measured at meteorological stations, and the data are only valid for the point of measurement. To overcome this problem, the highresolution gridded daily precipitation dataset from Asian Precipitation Highly Resolved Observational Data Integration Towards Evaluation of Water Resources (APHRODITE) database were used to the regionalization of Iran's precipitation regime. This database is being constructed by APHRODITE's water resources project in collaboration with the Research Institute for Humanity and Nature and the Meteorological Research Institute of the Japan Meteorological Agency. The APHRODITE project has released a high-resolution daily 
gridded precipitation dataset covering the Eurasian continent to develop state-of-the-art daily precipitation datasets on high-resolution grids (Yatagai et al. 2009). The data used in APHRODITE analysis were: (1) GTS-based data (the global summary of the day); (2) data precompiled by other projects or organizations; and (3) APHRODITE's own collection (Yatagai et al. 2012). The aim of the present study is to regionalize precipitation regimes in Iran by using principal component analysis and clustering analysis.

\section{Data and Methods}

Iran is located in the southwest of Asia. Its surface area is about $1,648,000 \mathrm{~km}^{2}$ and is approximately limited between latitude $25^{\circ} \mathrm{N}$ to $40^{\circ} \mathrm{N}$ and longitude $44^{\circ} \mathrm{E}$ to $64^{\circ} \mathrm{E}$. The two high mountain ranges of Zagros and Alborz in west and north, respectively, strikingly affect the temporal and spatial patterns of precipitation, and prevent much of the available moisture into the interior deserts (Alijani et al. 2008). Spatiotemporal precipitation patterns in Iran are significantly variable in attribution to complex terrains (i.e., mountains range, central deserts and coastal areas), geographic latitude, and several air masses that influence Iran throughout the year (Nazaripour and Mansouri Daneshvar 2014). The seasonal distribution of precipitation is controlled by the interaction of the tropical air mass from the Red Sea, the Mediterranean low pressures, the Siberian high pressure and the western passenger high pressures.

The APHRODITE daily precipitation gridded data for Middle East within 1951 to 2007 was extracted via APHRODITE's Water Resources web site (http://www.chikyu.ac.jp/precip/ products). This dataset covers an area of $20 \mathrm{E}$ to $65 \mathrm{E}$ and $15 \mathrm{~N}$ to $45 \mathrm{~N}$, and has a resolution of $0.25^{\circ} \times 0.25^{\circ}$, which has been clipped in 2,491 pixels over the Iran surface area (Fig. 1a). The distribution of annual long-term mean precipitation in Iran is shown in Fig. 1b. It can be seen that the Zagros and Alborz Mountain ranges have an important role in distribution and received precipitation in the country. The maximum annual received precipitation observed in northern Iran on the southwestern coast of the Caspian Sea, where the mean annual precipitation is over $1,300 \mathrm{~mm}$. In addition, on the Zagros Mountains, the mean annual precipitation is about $700 \mathrm{~mm}$. The lowest mean annual precipitation, less than $100 \mathrm{~mm}$, occurs in the central and southeastern parts of Iran.

The objective of principal component analysis (PCA) is to reduce the number of predictive variables and transform them into new variables, called principal components (PC). To better elucidate the influence of each original variable on the PCs, a rotational algorithm, such as the varimax rotation, was applied to obtain the rotated factor loadings (Jhajharia et al. 2013). Also, to apply the hierarchical clustering, the Euclidean distance measure for the observations and Ward's method for the linkage rule were used. Among the various distance measures and linkage rules that can be used in hierarchical cluster analysis, this combination has been shown to yield the most distinctive groups (Mansouri Daneshvar 2014).

\section{Results and Discussion}

\subsection{Interpretation of Mean Seasonal Precipitation Data}

In this study, we considered seasonal precipitation data with eight derived variables (Figs. 2 and 3). In these figures, the mean seasonal precipitation amount and its percentage have been interpolated over Iran. In the winter season, the highest precipitation amounts are recorded on Zagros mountain. During winter the southeastern parts of the country receives about $65 \%$ of 

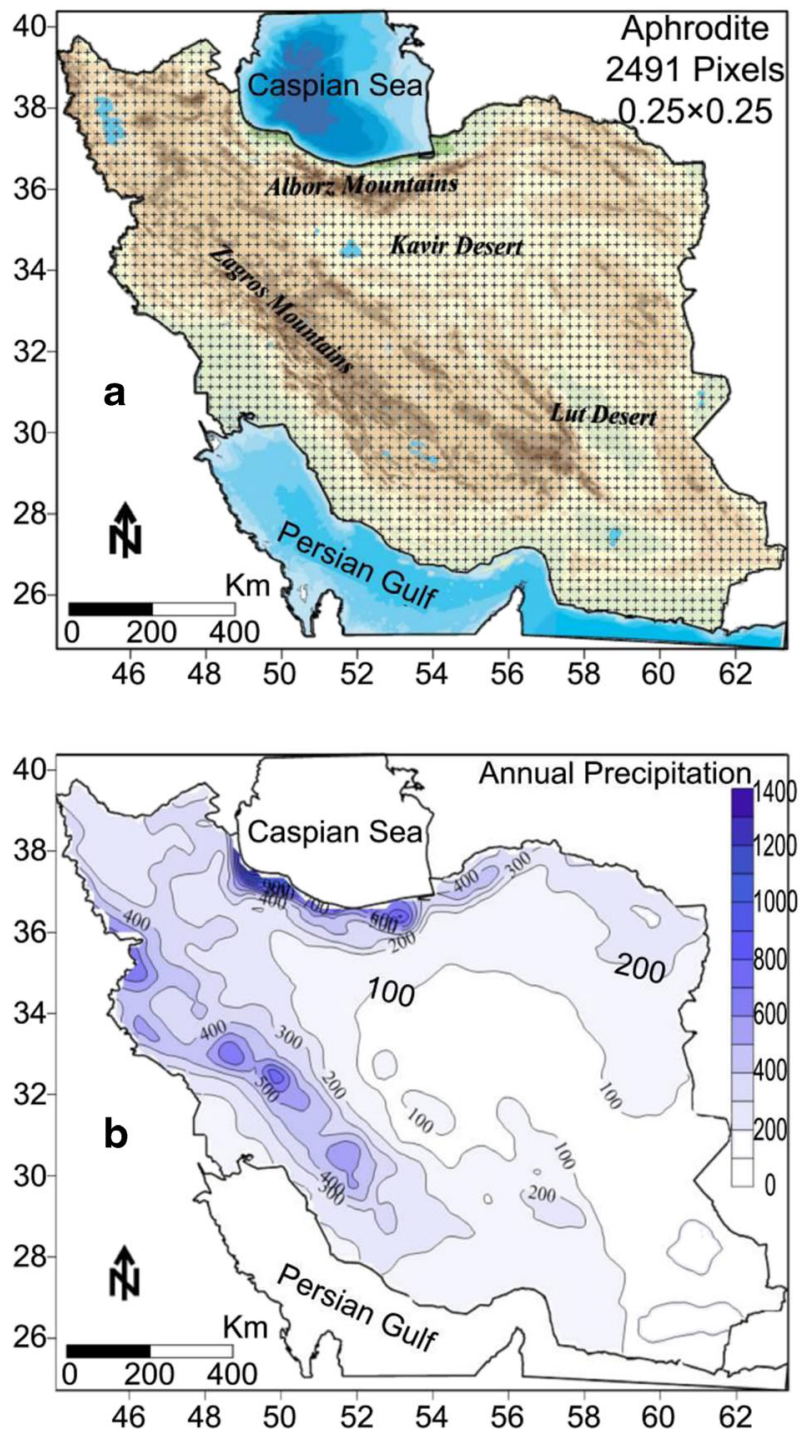

Fig 1 a The clipped APHRODITE dataset on the elevation terrain map of Iran containing 2,491 pixels with resolution of $0.25^{\circ} \times 0.25^{\circ}$; b Mean annual precipitation (mm) over Iran in years 1951 to 2007

total annual precipitation. The north and northwestern parts receive lower than $30 \%$ of the total annual precipitation. In the spring season, the maximum core precipitation, with more than $200 \mathrm{~mm}$, is shifted to the north and northwestern area (Fig. 2a to b). The spring precipitation decreases from the northwestern areas towards the southern regions. During this season, some regions of the northwestern part receive about $40 \%$ of the total annual precipitation (Fig. 2c to d). Due to subtropical high pressure, except of the northern areas and some regions in the southeastern part, summer is the driest season in Iran. The contribution of summer precipitation to the total annual precipitation in the southwestern coasts of the Caspian Sea and southeastern areas of Iran are about 24 and $21 \%$, respectively (Fig. 3a to b). 

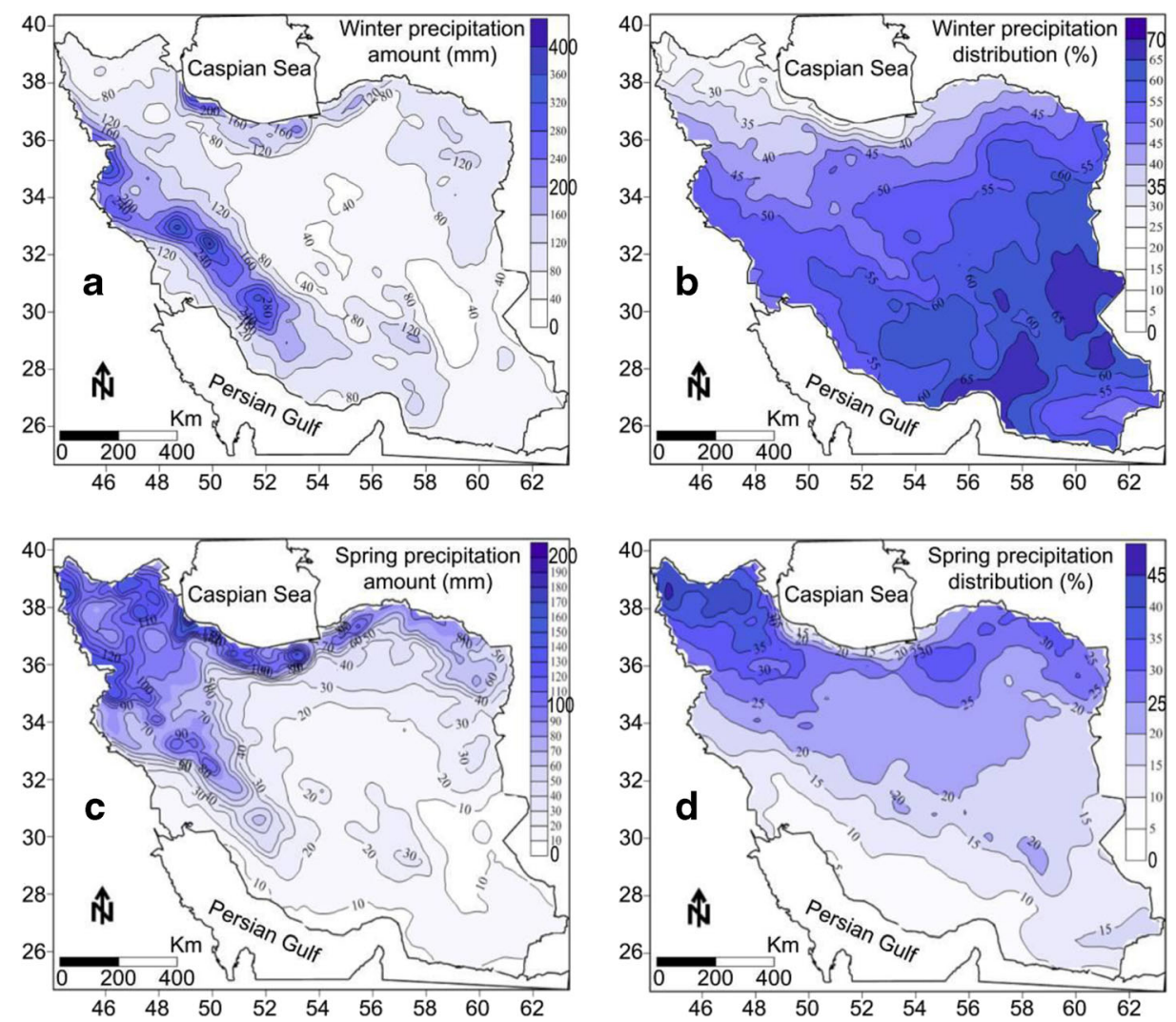

Fig. 2 Mean seasonal precipitation: a winter precipitation amount in $\mathrm{mm}$; b the percentage of winter precipitation distribution; c spring precipitation amount in $\mathrm{mm}$; $\mathbf{d}$ the percentage of spring precipitation distribution

The spatial and temporal share of autumn precipitation extends over the whole surface of Iran. Over $42 \%$ of the total annual precipitation occurs in the autumn season. The highest value of autumn precipitation occurs in the southwestern area of the Caspian Sea. The lowest contribution of autumn precipitation to the total precipitation is observed in the mid-eastern areas of Iran (Fig. $3 \mathrm{c}$ to d). According to the abovementioned statements, we can claim that the Iranian precipitation regimes present spatial variation. The northwestern areas receive most of the precipitation in the spring, while in the southeastern parts of the country most precipitation is recorded in the winter. At the southwestern parts of the Caspian Sea, the maximum precipitation percentage is observed in the autumn. The contribution of summer precipitation to the total received precipitation is high in the southeastern part of the country. In the present study, we focus on regionalizing the precipitation regimes in Iran, in order to detect homogenous sub-regions by using principal component analysis and hierarchical cluster analysis.

\subsection{Description of the Principal Component Analysis}

Data analysis first included calculation of the seasonal precipitation amount and percentage into each grid cell. Then, the S-mode of PCA was applied on the correlation matrix of seasonal precipitation with eight derived variables which have been mapped using GIS in Figs. 2 and 3. Use of the correlation matrix, as opposed to the covariance matrix, allows dry grids in the 

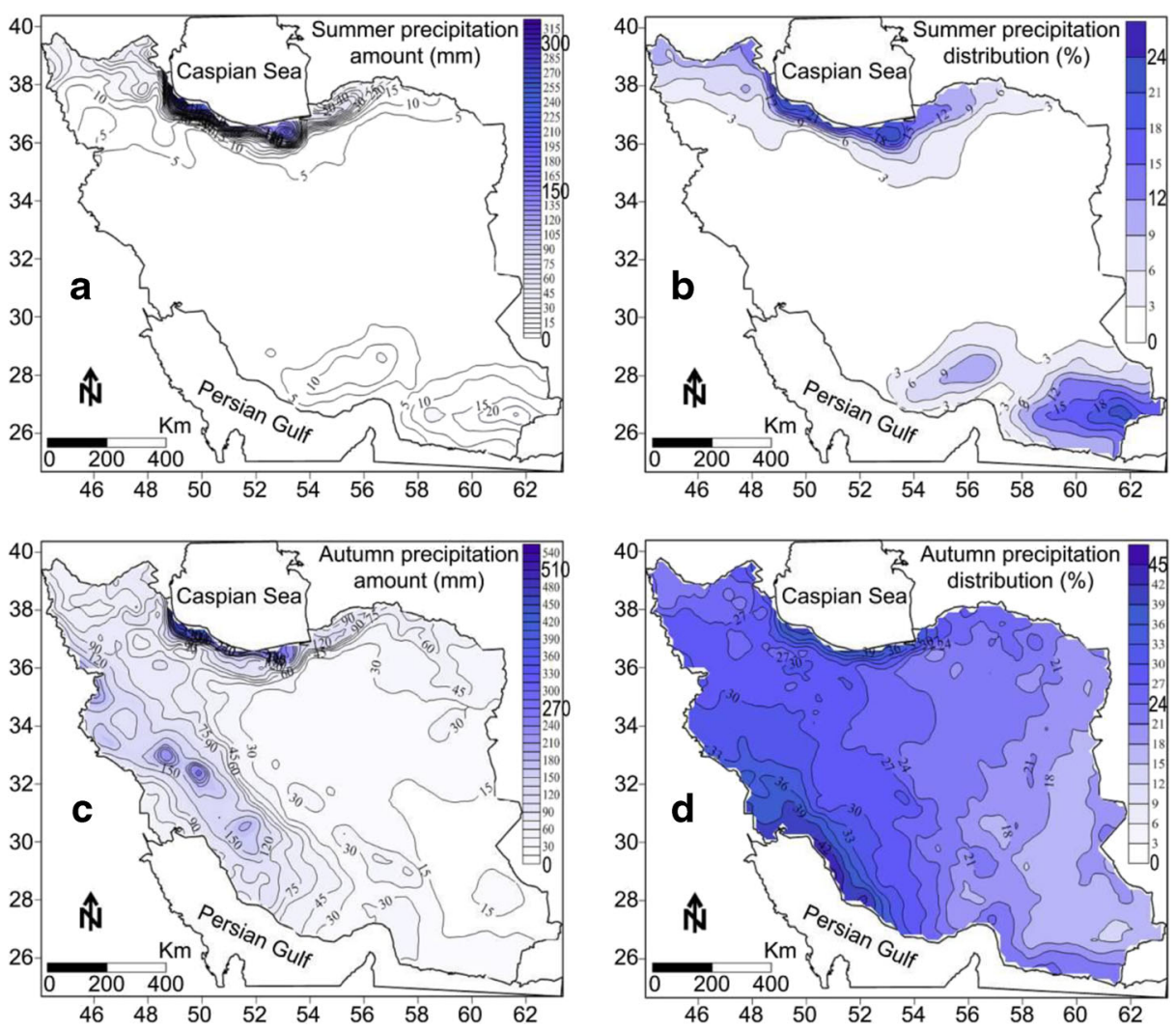

Fig. 3 Mean seasonal precipitation: a summer precipitation amount in $\mathrm{mm}$; b the percentage of summer precipitation distribution; c autumn precipitation amount in $\mathrm{mm}$; $\mathbf{d}$ the percentage of autumn precipitation distribution

deserts to be directly compared to relatively wet grids in the mountains (Comrie and Glenn 1998). The initial statistics are presented in Table 1, and the selection of principal components was based on the eigenvalues over one. The retained components were subjected to varimax rotation to enhance interpretability. The advantage of a varimax rotation is that it keeps the principal components uncorrelated (Jolliffe 1986; Wilks 1995; Paschalidou et al. 2009). An orthogonal rotation based on varimax criterion can be widely applied to obtain more spatially localized and uncorrelated principal components (Storch and Zwiers 1999). White et al. (1991), in their comparison of rotation techniques, found that oblique rotations generally produced the best results for climate regionalization. Miller and Goodrich (2007) found little difference between the oblique and orthogonal rotation methods, and preferred the orthogonal method because it tends to preserve the maximum loading of individual components (Cook et al. 1999; Frei and Robinson 1999; McCabe et al. 2004).

In this study, we used the recommendations of Miller and Goodrich (2007) to apply the rotated orthogonal based on varimax scores to achieve eigenvector-based regionalization regime of seasonal precipitation. In this regard, about three rotated components were considered based on scree plot and eigenvalues over 1.0, which have explained $88.95 \%$ of the total variance in the data. High loading values $(>0.7)$ were considered as important loadings and showed good correlations between the variables and the principal components (Table 2). Then, 
Table 1 Eigenvalues, explained variance and cumulative variance of eight principal components

\begin{tabular}{llll}
\hline PCs & \% of Variance & Eigenvalue & \% of Cumulative Variance \\
\hline PC1 & 47.207 & 3.777 & 47.207 \\
PC2 & 23.779 & 1.902 & 70.986 \\
PC3 & 17.961 & 1.437 & 88.948 \\
PC4 & 7.038 & 0.563 & 95.986 \\
PC5 & 3.297 & 0.264 & 99.283 \\
PC6 & 0.525 & 0.042 & 99.808 \\
PC7 & 0.192 & 0.015 & 100.000 \\
PC8 & $7.550 \mathrm{E}-16$ & $6.040 \mathrm{E}-17$ & 100.000 \\
\hline
\end{tabular}

the standardized rotated PC scores were calculated by using the regression method, as shown in Figs. 4a to c.

The PC1 loading value, which explains $47.2 \%$ of the total variance, has positive values on autumn precipitation, both as seasonal mean precipitation and percentage, and high positive values on winter precipitation. The standardized PC score shows high positive values in the southeastern part of Caspian Sea and Zagros mountain range, and negative values in the southeastern parts of the country. In the southwestern parts of the Caspian Sea, autumn precipitation is about six times higher than the mean precipitation in autumn. In addition, winter precipitation in the Zagros Mountains range is about four times higher than the mean precipitation in winter. The lowest PC score in the southeastern part of the country indicate low autumn and winter precipitation depth and autumn percentage of total precipitation.

The PC2 loading value, which accounts for $23.77 \%$ of the total variance, has high positive values on spring precipitation amount and percentage. The PC2 has negative values on winter precipitation percentage. In spatial view, the positive PC2 scores are observed in the northwestern and northeastern parts of Iran. The highest values of PC2 are located on the northwest part of the country, and indicate the highest contribution of spring precipitation and low contribution of winter precipitation in the total precipitation. The high precipitation in the spring in the northwestern parts of Iran is attributed to the convective mechanism due to surface heating and availability to air humidity in the atmosphere. In contrast, the negative PC2 score over the mid-southern parts imply that the amount and contribution of spring precipitation are lower than the winter precipitation percentage. In the commencement of warm season and displacement of western wind waves northward, tropical air mass and subtropical

Table 2 Loading values of varimax rotated principal components

\begin{tabular}{lrrr}
\hline Components & PC1 & PC2 & PC3 \\
\hline Percentage of Winter Precipitation & -0.264 & -0.865 & -0.330 \\
Percentage of Spring Precipitation & -0.182 & 0.971 & -0.065 \\
Percentage of Summer Precipitation & -0.144 & 0.079 & 0.937 \\
Percentage of Autumn Precipitation & 0.824 & 0.136 & -0.055 \\
Mean Winter Precipitation & 0.916 & -0.034 & -0.006 \\
Mean Spring Precipitation & 0.508 & 0.781 & 0.207 \\
Mean Summer Precipitation & 0.303 & 0.168 & 0.869 \\
Mean Autumn Precipitation & 0.916 & 0.192 & 0.317 \\
\hline
\end{tabular}



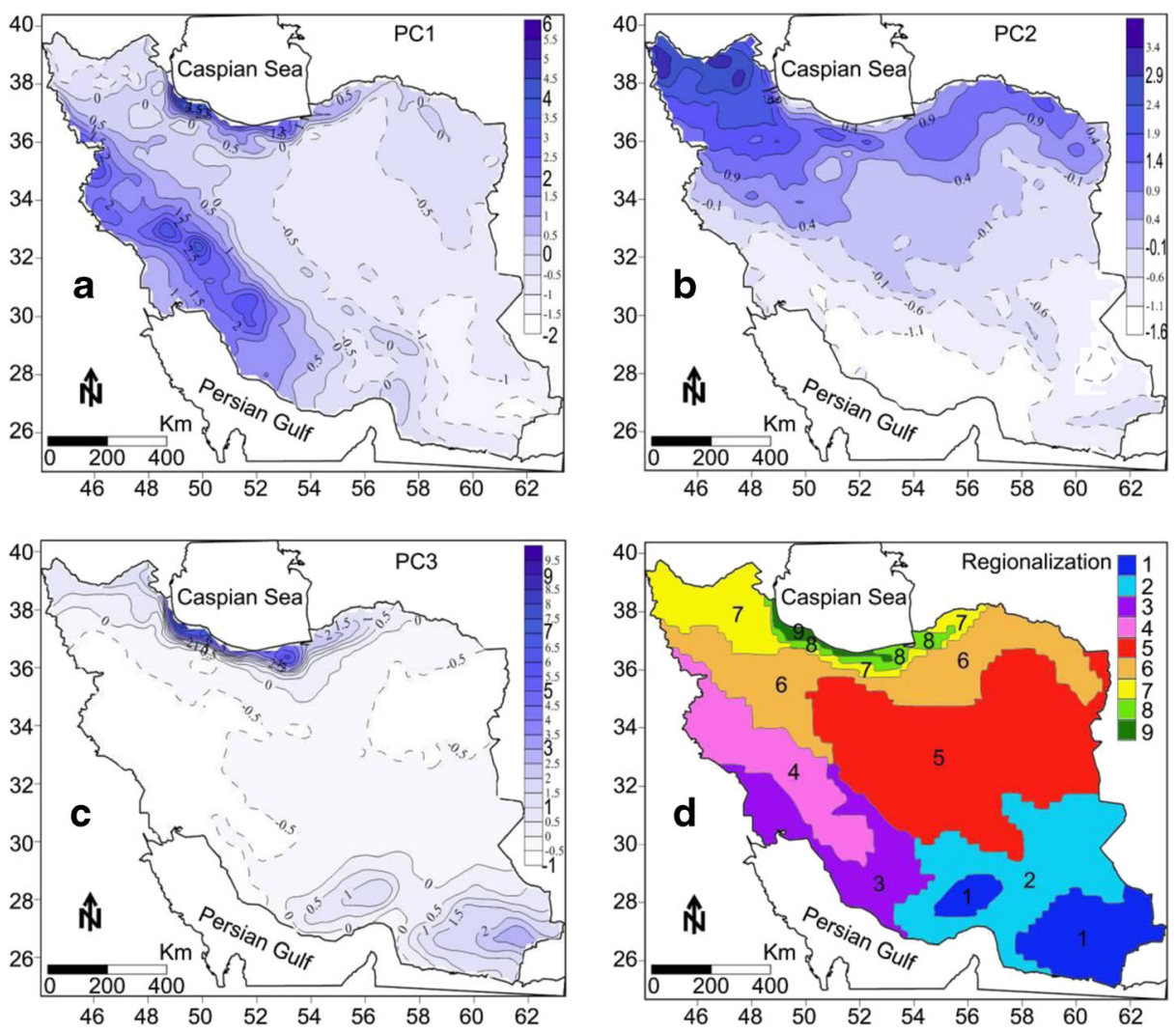

Fig. 4 a Spatial distribution of rotated score of PC1; b spatial distribution of rotated score of PC2; c spatial distribution of rotated score of PC3; d spatial regionalization of precipitation regimes over Iran

high-pressure systems govern the region from the southward direction. As a result, the pressure gradient and instabilities that occur during the cold season decrease.

The PC3 loading value, with $17.96 \%$ of explained variance, has positive values for amount and percentage of summer precipitation. As Fig. $4 \mathrm{c}$ shows, the southern parts of the Caspian Sea and the southeastern areas of Iran have positive scores. In these regions, the amount and contribution of summer precipitation is relatively high. The main source of moisture for precipitation in these areas comes from the Caspian and Oman Sea. While apart from the above two mentioned regions, the PC3 scores are negative in all other parts of Iran, indicating low amount and contribution of summer precipitation in the total precipitation. In comparison to the other PC scores, the difference between the highest and lowest PC3 scores is relatively high. This implies high spatial variability of summer precipitation.

\subsection{Regionalization of Mean Seasonal Precipitation Data}

To identify the homogeneous precipitation regime, we applied HCA according to three abovementioned PC scores. The classification was achieved by hierarchical, agglomerative cluster analysis using Ward's method. Ward's method was selected, because it typically outperforms other algorithms in terms of separation, to give relatively dense clusters with small within group variance (Mansouri Daneshvar et al. 2013). Based on the HCA, about nine 
distinct regions were recognized and were mapped by using GIS (Fig. 4d). In this regard, about nine groups (regions) were identified spatially through Iran country. To check the statistical significance of the identified groups (regions), the non-parametric Kolmogorov-Smirnov test was applied to group distribution with the null hypothesis that the distributions are the same. The results of the test are given in Table 3; it can be seen that most differences between the region distribution are in the $1 \%$ level of significance at four seasons.

Table 3 The results of Kolmogorov-Smirnov test applied to check group's distribution of seasonal precipitation percentage in the nine regions

\begin{tabular}{|c|c|c|c|c|c|c|c|c|c|c|}
\hline & & Region1 & Region2 & Region3 & Region4 & Region5 & Region6 & Region7 & Region8 & Region9 \\
\hline \multirow[t]{9}{*}{ Winter } & Region1 & & $P<0.05$ & $P=0.3$ & $P<0.01$ & $P<0.05$ & $P<0.01$ & $P<0.01$ & $P<0.01$ & $P<0.01$ \\
\hline & Region2 & & & $P=0.11$ & $P<0.01$ & $P<0.1$ & $P<0.01$ & $P<0.01$ & $P<0.01$ & $P<0.01$ \\
\hline & Region3 & & & & $P<0.05$ & $P=0.52$ & $P<0.01$ & $P<0.01$ & $P<0.01$ & $P<0.01$ \\
\hline & Region4 & & & & & $P<0.1$ & $P<0.01$ & $P<0.01$ & $P<0.01$ & $P<0.01$ \\
\hline & Region5 & & & & & & $P<0.01$ & $P<0.01$ & $P<0.01$ & $P<0.01$ \\
\hline & Region6 & & & & & & & $P<0.01$ & $P<0.01$ & $P<0.01$ \\
\hline & Region7 & & & & & & & & $P=0.61$ & $P<0.01$ \\
\hline & Region8 & & & & & & & & & $P<0.01$ \\
\hline & Region9 & & & & & & & & & \\
\hline \multirow[t]{9}{*}{ Springer } & Region1 & & $P<0.05$ & $P<0.01$ & $P<0.05$ & $P<0.01$ & $P<0.01$ & $P<0.01$ & $P<0.01$ & $P<0.01$ \\
\hline & Region2 & & & $P<0.01$ & $P<0.05$ & $P<0.01$ & $P<0.01$ & $P<0.01$ & $P<0.01$ & $P<0.01$ \\
\hline & Region3 & & & & $P<0.01$ & $P<0.01$ & $P<0.01$ & $P<0.01$ & $P<0.01$ & $P<0.01$ \\
\hline & Region4 & & & & & $P<0.05$ & $P<0.01$ & $P<0.01$ & $P<0.01$ & $P<0.01$ \\
\hline & Region5 & & & & & & $P<0.01$ & $P<0.01$ & $P<0.01$ & $P<0.01$ \\
\hline & Region6 & & & & & & & $P<0.01$ & $P<0.01$ & $P<0.01$ \\
\hline & Region7 & & & & & & & & $P<0.01$ & $P<0.01$ \\
\hline & Region8 & & & & & & & & & $P<0.01$ \\
\hline & Region9 & & & & & & & & & \\
\hline \multirow[t]{9}{*}{ Summer } & Region1 & & $P<0.01$ & $P<0.01$ & $P<0.01$ & $P<0.01$ & $P<0.01$ & $P<0.05$ & $P<0.01$ & $P<0.01$ \\
\hline & Region2 & & & $P<0.01$ & $P<0.01$ & $P<0.01$ & $P<0.01$ & $P<0.01$ & $P<0.01$ & $P<0.01$ \\
\hline & Region3 & & & & $P=0.15$ & $P<0.05$ & $P<0.01$ & $P<0.01$ & $P<0.01$ & $P<0.01$ \\
\hline & Region4 & & & & & $P<0.01$ & $P<0.01$ & $P<0.01$ & $P<0.01$ & $P<0.01$ \\
\hline & Region5 & & & & & & $P<0.01$ & $P<0.01$ & $P<0.01$ & $P<0.01$ \\
\hline & Region6 & & & & & & & $P<0.01$ & $P<0.01$ & $P<0.01$ \\
\hline & Region7 & & & & & & & & $P<0.01$ & $P<0.01$ \\
\hline & Region8 & & & & & & & & & $P<0.01$ \\
\hline & Region9 & & & & & & & & & \\
\hline \multirow[t]{9}{*}{ Autumn } & Region1 & & $P=0.52$ & $P<0.01$ & $P<0.01$ & $P<0.01$ & $P<0.01$ & $P<0.01$ & $P<0.01$ & $P<0.01$ \\
\hline & Region2 & & & $P<0.01$ & $P<0.01$ & $P<0.05$ & $P<0.01$ & $P<0.01$ & $P<0.01$ & $P<0.01$ \\
\hline & Region3 & & & & $P<0.05$ & $P<0.05$ & $P<0.01$ & $P<0.01$ & $P<0.01$ & $P<0.01$ \\
\hline & Region4 & & & & & $P<0.05$ & $P<0.01$ & $P<0.01$ & $P<0.01$ & $P<0.01$ \\
\hline & Region5 & & & & & & $P<0.01$ & $P<0.01$ & $P<0.01$ & $P<0.01$ \\
\hline & Region6 & & & & & & & $P<0.05$ & $P<0.01$ & $P<0.01$ \\
\hline & Region7 & & & & & & & & $P<0.01$ & $P<0.01$ \\
\hline & Region8 & & & & & & & & & $P<0.01$ \\
\hline & Region9 & & & & & & & & & \\
\hline
\end{tabular}


In the winter season, the distributions were the same in the southern regions 1,2 and 3, and the southern areas of Caspian Sea, regions 7 and 8 (Fig. 4d). The distribution of spring precipitation in all regions was different at the confidence levels of $99 \%$. Therefore, the distribution of summer precipitation was statistically different in all regions. For regions 3 and 4, the differences were not significant because the contribution of summer precipitation to mentioned regions was very low $(<1 \%)$. The distribution of autumn precipitation to the total one was different in recognized regions except for regions 1 and 2. According to the results of the Kolmogorov-Smirnov test on seasonal percentage of precipitation distribution in the regions, it can be concluded that the precipitation regimes in the regions are different. Distribution of seasonal precipitation percentage for each region is shown in Fig. 5, and the statistical data of nine regions are summarized in Tables 4 and 5.

In the southeast part of the country, Region 1 extends to about $9.4 \%$ of Iran surface area. This region is a very dry region, with an average total precipitation of $105 \mathrm{~mm}$, which contains most parts of the southeast Iran. The main rainy season is observed in the winter, with about $56.7 \%$ of the total precipitation. In the winter, this region is affected by the southern track of Mediterranean and Red Sea cyclones. The contributions of summer precipitation values to total precipitation in regions 7,8 and 9 are obtained as the highest values in Iran. These high precipitation values are affected by southern summer monsoon.

Region 2 includes about $16 \%$ of Iran surface area, extending in the southeastern parts of Iran. This region is another dry region in Iran with mean total precipitation of $111 \mathrm{~mm}$. In accordance to most regions, the main rainy season in this region occurs in winter, with about $64 \%$ of the total precipitation received in this season. The contribution of summer precipitation to the total precipitation is equal to $3 \%$.

The foothills of Zagros Mountains in region 3 extend to about $9.1 \%$ of Iran surface area. The mean annual precipitation is recorded at $234.7 \mathrm{~mm}$ in this region. The
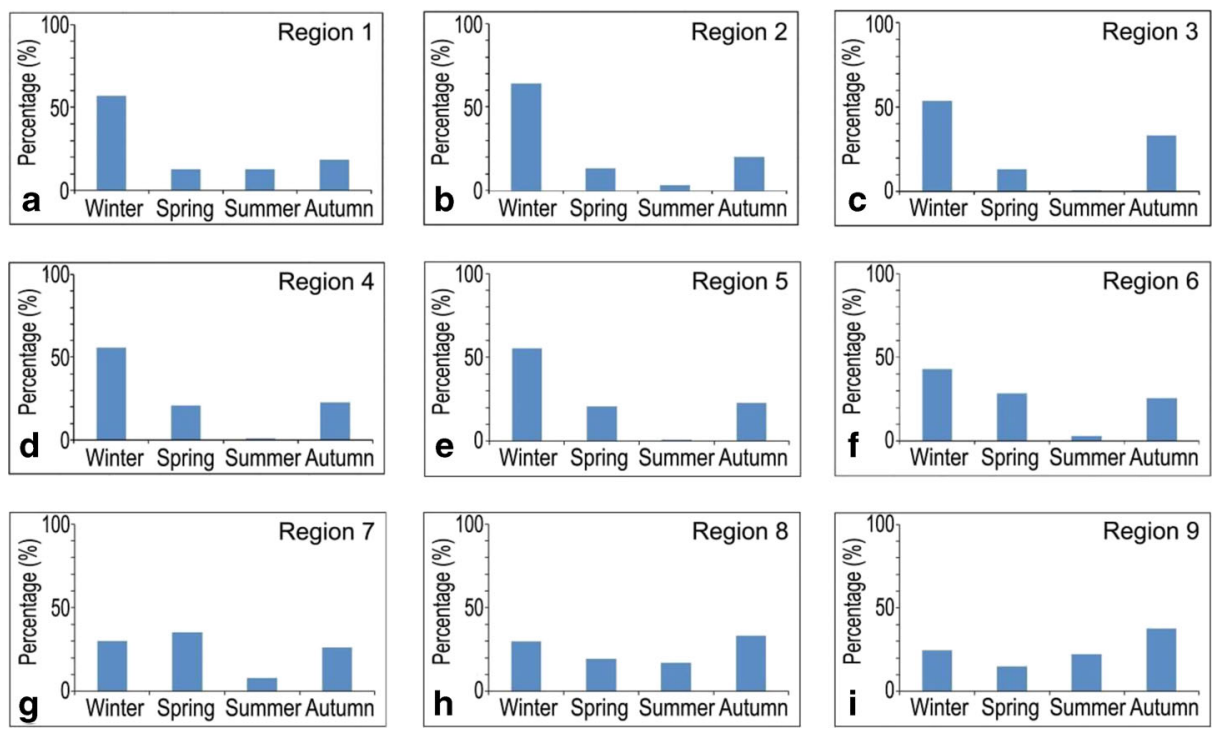

Fig. 5 Total percentage of seasonal precipitation within nine regions a region 1; b region 2; c region 3; d region 4; e region 5; f region 6; $\mathbf{g}$ region 7 ; $\mathbf{h}$ region 8 ; i region 9 
Table 4 Mean annual and seasonal precipitation and their standard deviation (SD), maximum (Max) and minimum (Min) values in the nine regions

\begin{tabular}{|c|c|c|c|c|c|c|}
\hline \multirow[t]{2}{*}{ Regions } & \multirow[t]{2}{*}{ Statistics } & \multicolumn{5}{|c|}{ Mean precipitation $(\mathrm{mm})$} \\
\hline & & Annual & Winter & Spring & Summer & Autumn \\
\hline \multirow[t]{4}{*}{ Region 1} & Mean & 105.5 & 61.3 & 13.1 & 12.2 & 18.8 \\
\hline & SD & 28.9 & 20.4 & 3.4 & 4.1 & 6.6 \\
\hline & Max & 208.6 & 126.8 & 27.8 & 27 & 41 \\
\hline & Min & 45.3 & 28.9 & 6.2 & 2.9 & 7.2 \\
\hline \multirow[t]{4}{*}{ Region 2} & Mean & 111 & 71.9 & 12.5 & 3.3 & 23.2 \\
\hline & $\mathrm{SD}$ & 54.3 & 35 & 5.6 & 2.8 & 14.1 \\
\hline & Max & 268 & 173.6 & 39 & 12.8 & 57.6 \\
\hline & Min & 41.2 & 25.5 & 6.1 & 0.4 & 5.9 \\
\hline \multirow{4}{*}{ Region 3} & Mean & 234.7 & 131 & 21.6 & 1.7 & 80.2 \\
\hline & $\mathrm{SD}$ & 57 & 35.8 & 10.1 & 1.4 & 18.6 \\
\hline & Max & 385.7 & 221.7 & 54.3 & 6.1 & 122.9 \\
\hline & Min & 123.9 & 61 & 7.2 & 0.1 & 46.5 \\
\hline \multirow[t]{4}{*}{ Region 4} & Mean & 460.9 & 236.8 & 74.3 & 2.1 & 147.6 \\
\hline & $\mathrm{SD}$ & 86 & 49.3 & 28.9 & 1.3 & 26.2 \\
\hline & Max & 780.3 & 411.9 & 148.5 & 12.1 & 259.1 \\
\hline & Min & 300 & 158.4 & 20.4 & 0.3 & 98.9 \\
\hline \multirow[t]{4}{*}{ Region 5} & Mean & 117 & 64.7 & 24.9 & 1.1 & 26.2 \\
\hline & $\mathrm{SD}$ & 41.5 & 24.1 & 10.3 & 0.84 & 9.4 \\
\hline & Max & 261.6 & 132.1 & 69.9 & 6.7 & 66.8 \\
\hline & Min & 57 & 33.3 & 10.7 & 0.1 & 10.7 \\
\hline \multirow[t]{4}{*}{ Region 6} & Mean & 231.6 & 97.3 & 67.6 & 5.8 & 60.7 \\
\hline & $\mathrm{SD}$ & 85.6 & 34.1 & 25.7 & 4 & 28.5 \\
\hline & Max & 454 & 188.7 & 141.1 & 26.6 & 135.8 \\
\hline & Min & 85.9 & 40.2 & 22.4 & 0.79 & 19.9 \\
\hline \multirow[t]{4}{*}{ Region 7} & Mean & 296.2 & 89.3 & 104.1 & 24.4 & 78.3 \\
\hline & $\mathrm{SD}$ & 61.1 & 26.1 & 21.8 & 11.5 & 20. \\
\hline & Max & 537.2 & 162.9 & 162.2 & 63 & 163.4 \\
\hline & Min & 182 & 49.7 & 44.2 & 6.1 & 42.2 \\
\hline \multirow[t]{4}{*}{ Region 8} & Mean & 509.4 & 149.6 & 99.4 & 89.5 & 170.8 \\
\hline & $\mathrm{SD}$ & 104.6 & 21.4 & 21.4 & 34 & 45.1 \\
\hline & Max & 706.3 & 198.7 & 156.3 & 160.3 & 279.7 \\
\hline & Min & 316 & 111.6 & 55.3 & 39.9 & 107 \\
\hline \multirow[t]{4}{*}{ Region 9} & Mean & 972 & 236.3 & 144.5 & 218.7 & 372.3 \\
\hline & $\mathrm{SD}$ & 169.3 & 39.7 & 25.7 & 43.4 & 80.6 \\
\hline & Max & $1,408.4$ & 318.8 & 207.9 & 337.4 & 544.1 \\
\hline & Min & 738.5 & 184.5 & 88.9 & 158.5 & 244.7 \\
\hline
\end{tabular}

maximum percentage of total precipitation falls in winter $(55.3 \%)$ followed by autumn $(34.2 \%)$. The contribution of spring and summer to total precipitation is very low $(9.5$ and $0.8 \%$, respectively). 
Table 5 Seasonal precipitation percentage of total amount and their standard deviation (SD), maximum (Max) and minimum (Min) values into nine regions

\begin{tabular}{|c|c|c|c|c|c|}
\hline \multirow[t]{2}{*}{ Regions } & \multirow[t]{2}{*}{ Statistics } & \multicolumn{4}{|c|}{ Seasonal precipitation percentage $(\%)$} \\
\hline & & Winter & Spring & Summer & Autumn \\
\hline \multirow[t]{4}{*}{ Region 1} & Mean & 56.7 & 12.5 & 12.4 & 18.2 \\
\hline & $\mathrm{SD}$ & 4.69 & 2.1 & 3.8 & 2.5 \\
\hline & Max & 66.7 & 17.6 & 22 & 25 \\
\hline & Min & 45.6 & 8.3 & 6.4 & 14.2 \\
\hline \multirow[t]{4}{*}{ Region 2} & Mean & 63.9 & 13 & 3 & 20 \\
\hline & $\mathrm{SD}$ & 2.7 & 3.7 & 1.8 & 3.4 \\
\hline & $\operatorname{Max}$ & 69.5 & 23.2 & 7.7 & 31.9 \\
\hline & Min & 57.1 & 6.4 & 0.4 & 14.1 \\
\hline \multirow[t]{4}{*}{ Region 3} & Mean & 55.3 & 9.5 & 0.8 & 34.2 \\
\hline & $\mathrm{SD}$ & 4 & 3 & 0.75 & 5.3 \\
\hline & Max & 63.9 & 18.4 & 3.7 & 45.6 \\
\hline & Min & 47.6 & 4.7 & 0.09 & 24.2 \\
\hline \multirow[t]{4}{*}{ Region 4} & Mean & 51.3 & 16.1 & 0.49 & 31.9 \\
\hline & $\mathrm{SD}$ & 4.1 & 5.2 & 0.29 & 2.1 \\
\hline & Max & 58.8 & 28.6 & 2.3 & 40.1 \\
\hline & Min & 39.6 & 6.1 & 0.1 & 28.5 \\
\hline \multirow[t]{4}{*}{ Region 5} & Mean & 55.3 & 20.7 & 1 & 22.8 \\
\hline & $\mathrm{SD}$ & 5 & 2.1 & 0.63 & 3.4 \\
\hline & $\operatorname{Max}$ & 67.2 & 26.4 & 3.7 & 31.2 \\
\hline & Min & 43.7 & 14.5 & 0.08 & 15.5 \\
\hline \multirow[t]{4}{*}{ Region 6} & Mean & 42.9 & 28.5 & 2.8 & 25.6 \\
\hline & $\mathrm{SD}$ & 4.2 & 2.8 & 2 & 3.5 \\
\hline & $\operatorname{Max}$ & 55.5 & 34.7 & 11 & 32.5 \\
\hline & Min & 34.7 & 20.8 & 0.3 & 17.5 \\
\hline \multirow[t]{4}{*}{ Region 7} & Mean & 30.2 & 35.3 & 8 & 26.3 \\
\hline & $\mathrm{SD}$ & 4.8 & 6.4 & 3 & 2.5 \\
\hline & $\operatorname{Max}$ & 40 & 46.2 & 17.6 & 35.5 \\
\hline & Min & 22.1 & 19 & 2.5 & 20.9 \\
\hline \multirow[t]{4}{*}{ Region 8} & Mean & 30 & 19.5 & 17 & 33.3 \\
\hline & $\mathrm{SD}$ & 3.5 & 3 & 3.3 & 3.6 \\
\hline & $\operatorname{Max}$ & 37.6 & 24.4 & 22.7 & 42.3 \\
\hline & Min & 23.8 & 11.2 & 12 & 26.8 \\
\hline \multirow[t]{4}{*}{ Region 9} & Mean & 24.6 & 15.1 & 22.4 & 37.7 \\
\hline & $\mathrm{SD}$ & 1.8 & 2.3 & 1.5 & 3.1 \\
\hline & $\operatorname{Max}$ & 27.5 & 20 & 26.2 & 41.7 \\
\hline & Min & 21.7 & 11.5 & 20.6 & 30.4 \\
\hline
\end{tabular}

Region 4 includes the highest part of the Zagros Mountain ranges. This region is a special region due to its high altitude and significant rainfall depths of $460.9 \mathrm{~mm}$. The main rainy season in this region occurs in winter. This region is strongly affected by southwest moist spells and warm airflows coming during Red Sea low pressure, in combination with the winter 
southern track of Mediterranean cyclones. The contribution of summer precipitation to total precipitation is negligible $(0.49 \%)$.

Region 5 includes the largest region that covers about $29.7 \%$ of Iran surface area. It contains the central parts of Iran. Due to shadow effects of two mountain ranges, Zagros in the west and Alborz in the north, mean annual precipitation is about $117 \mathrm{~mm}$. The main rainy season occurs in the winter and the contribution of other seasons to total precipitation is relatively low.

Region 6 includes some parts extended from northwest to northeast. It covers $16.6 \%$ of Iran surface area. The mean annual precipitation is recorded at about $231.6 \mathrm{~mm}$. The main rainy season occurs in the winter with contribution of $42.9 \%$. The percentage of spring and autumn seasons in total precipitation is observed somewhat similar (28.5 and $25.6 \%$, respectively). The northwestern parts of Iran present the highest contribution to the spring precipitation and the lowest contribution to the winter precipitation.

Region 7 includes the northwest and the northeast parts of Iran, which are characterized by abundant precipitation in the spring season. This region experiences a mean annual precipitation of $296.2 \mathrm{~mm}$. The contribution of spring precipitation to the total precipitation is recorded at about $35.3 \%$, while the percentages of winter and autumn are about 30.2 and $26.3 \%$, respectively. The share of summer precipitation is relatively low $(8 \%)$. The highest convective mechanism in this region is attributed to land surface heating and atmospheric air humidity in the spring season. Another reason for the maximum precipitation in spring is that westerly wind waves do not completely leave the region.

Region 8 contains the southern parts of the Caspian Sea. The mean annual precipitation is higher than all the other regions except of region $9(509.4 \mathrm{~mm})$. This region covers about $1.5 \%$ of Iran land surface. The highest precipitation season is the autumn with contribution of $33.3 \%$ to the total precipitation. At the end of the summer season, the Caspian Sea water is strongly heated. The Siberian high-pressure anticyclone system brings dry cold air to region 9. Then, the interaction between dry cold air masses and moist warm air over the Caspian Sea results in air turbulence, atmospheric instabilities and orographic precipitation events in the region. The Alborz Mountain range in the southern coast of the Caspian Sea blocks the southward northern airflows and supports instabilities.

Along region 9, the southwestern part of Caspian Sea is characterized by abundant precipitation. Region 9 covers only $0.8 \%$ of Iran surface area. In this region, the mean annual precipitation is about $972 \mathrm{~mm}$, with a relatively high standard deviation of $169 \mathrm{~mm}$. The most abundant precipitation occurs in autumn. The contribution of summer precipitation to total precipitation is the highest one among all regions $(22.4 \%)$. The high gradient of pressures between cold air masses originating from Eastern Europe and warm air upon the Caspian Sea in autumn season results to the high precipitation amounts in the southwestern parts of the Caspian Sea.

The results of clustered regions resulting in Iran in comparison to previous works in the area (i.e., Domroes et al. 1998; Dinpashoh et al. 2004; Raziei et al. 2008) seem to compare well. The aforementioned references have investigated the precipitation clustering based on station datasets without any gridded datasets. Dataset of meteorological and climatic stations are only valid for the point of measurement. Furthermore, meteorological stations are not distributed evenly across Iran surface area, with lower density observed towards the central and eastern parts. The uneven distribution makes it difficult to spatially assess and regionalize Iran's precipitation regime. Hence, APHRODITE project, with a high-resolution daily gridded precipitation dataset is an accurate source in precipitation clustering. 


\section{Conclusion}

Precipitation regimes were regionalized for Iran by using Principal Component Analysis with varimax rotation based on eight seasonal precipitation-based variables during years 1951 to 2007. Three principal components were extracted based on scree plot and eigenvalues higher than one. Three rotated components, which explain $88.95 \%$ of the total variance in the data, were used to calculate the PC scores. According to the results, the main precipitation regime is in the winter season. In some parts of southern and southeastern of Iran, more than half of the total precipitation occurs in the winter. With moving away from the mentioned regions to the north and Caspian Sea coast, the contribution of autumn precipitation to total one becomes higher than winter precipitation. The precipitation regime of northwestern parts of Iran is classified in spring season. The contribution of summer precipitation to total precipitation is noticeable in the southern parts of Caspian Sea and Southeastern areas. By applying hierarchical cluster analysis on rotated principal component scores, about nine homogenous precipitation regimes were identified. This study showed that the APHRODITE dataset potentially could be used for regionalization of precipitation regimes in Iran. According to the results, use of this dataset in order to group precipitation regimes is recommended for arid and semi-arid regions of mid-latitudes, especially in the Middle East countries, while its utilization in the humid and sub-humid regions needs to be further studied in the future.

Acknowledgments We thank the anonymous reviewers for suggestions on data analyses and interpretations. We are very grateful to the editor-in-chief for superior recommendations and technical annotations.

\section{References}

Alijani B, O’Brien J, Yarnal B (2008) Spatial analysis of precipitation intensity and concentration in Iran. Theor Appl Climatol 94(1-2):107-124

Arriaga-Ramírez S, Cavazos T (2010) Regional trends of daily precipitation indices in northwest Mexico and southwest United States. J Geophys Res 115:D14111. doi:10.1029/2009JD013248

Astel A, Mazerski J, Polkowska Z, Namienik J (2004) Application of PCA and time series analysis in studies of precipitation in Tricity (Poland). Adv Environ Res 8:337-349

Beguería S, Vicente-Serrano SM, López-Moreno JI, García-Ruiz JM (2009) Annual and seasonal mapping of peak intensity, magnitude and duration of extreme precipitation events across a climatic gradient, northeast Spain. Int J Climatol 29(12):1759-1779

Camberlin P, Diop M (2003) Application of daily rainfall principal component analysis to the assessment of the rainy season characteristics in Senegal. Clim Res 23:159-169

Cannon AJ, Whitfield PH, Lord ER (2002) Synoptic map-pattern classification using recursive partitioning and principal component analysis. Mon Weather Rev 130:1187-1206

Chen LJ, Chen DL, Wang HJ, Yan JH (2009) Regionalization of precipitation regimes in China. Atmos Ocean Sci Lett 2(5):301-307

Cheung WH, Senay GB, Singh A (2008) Trends and spatial distribution of annual and seasonal rainfall in Ethiopia. Int J Climatol 28(13):1723-1734

Comrie AC, Glenn EC (1998) Principal components-based regionalization of precipitation regimes across the southwest United States and northern Mexico, with an application to monsoon precipitation variability. Clim Res 10(3):201-215

Cook ER, Meko DM, Stahle DW, Cleaveland MK (1999) Drought reconstructions for the continental United States. J Clim 12(4):1145-1162

Dimri AP, Dash SK (2012) Wintertime climatic trends in the western Himalayas. Clim Chang 111(3-4):775-800

Dinpashoh Y, Fakheri-Fard A, Moghaddam M, Jahanbakhsh S, Mirnia M (2004) Selection of variables for the purpose of regionalization of Iran's precipitation climate using multivariate methods. J Hydrol 297(1-4): $109-123$ 
Dinpashoh Y, Mirabbasi R, ASCE SM, Jhajharia D, Abianeh HZ, Mostafaeipour A (2014) Effect of short-term and long-term persistence on identification of temporal trends. J Hydrol Eng ASCE 19(3):617-625

Domroes M, Kaviani M, Schaefer D (1998) An analysis of regional and intra-annual precipitation variability over Iran using multivariate statistical methods. Theor Appl Climatol 61(3-4):151-159

Frei A, Robinson DA (1999) Northern hemisphere snow extent: regional variability 1972-1994. Int J Climatol 19(14): $1535-1560$

Giannini A, Saravanan R, Chang P (2003) Oceanic forcing of Sahel rainfall on interannual to interdecadal time scales. Science 302:1027-1030

Gong X, Richman MB (1995) On the application of cluster analysis to growing season precipitation data in North America East of the Rockies. J Clim 8:897-931

Guhathakurta P, Rajeevan M (2008) Trends in the rainfall pattern over India. Int J Climatol 28:1453-1469

Halkidi M, Batistakis Y, Vazirgiannis M (2001) On clustering validation techniques. J Intell Inf Syst 17(2-3): $107-145$

Hsieh WW (2001) Nonlinear principal component analysis by neural networks. Tellus A 53:599-615

Jain SK, Kumar V (2012) Trend analysis of rainfall and temperature data for India. Curr Sci 102(1):37-49

Jhajharia D, Yadav BK, Maske S, Chattopadhyay S, Kar AK (2012) Identification of trends in rainfall, rainy days and $24 \mathrm{~h}$ maximum rainfall over subtropical Assam in Northeast India. Compt Rendus Geosci 344(1):1-13

Jhajharia D, Chattopadhyay S, Choudhary RR, Dev V, Singh VP, Lal S (2013) Influence of climate on incidences of malaria in the Thar Desert, northwest India. Int J Climatol 33:312-325

Jolliffe IT (1986) Principal component analysis. Springer, New York, p 271 pp

Kansakar SR, Hannah DM, Gerrard AJ, Rees G (2004) Spatial pattern in the precipitation regimes of Nepal. Int J Climatol 24(13):1645-1659

Kassile T (2013) Trend analysis of monthly rainfall data in central zone. J Math Stat 9(1):1-11

Longobardi A, Villani P (2009) Trend analysis of annual and seasonal rainfall time-series in the Mediterranean area. Int J Climatol 30(10):1538-1546

López-Moreno JI, Vicente-Serrano SM, Angulo-Martínez M, Beguería S, Kenawy A (2010) Trends in daily precipitation on the northeastern Iberian Peninsula, 1955-2006. Int J Climatol 30(7):1026-1041

Mansouri Daneshvar MR (2014) Climatic impacts on hydrogeochemical characteristics of mineralized springs: a case study of Garab travertine zone in northeast of Iran. Arab J Geosci. doi:10.1007/s12517-014-1536-2

Mansouri Daneshvar MR, Bagherzadeh A, Alijani B (2013) Application of multivariate approach in agrometeorological suitability zonation at northeast semiarid plains of Iran. Theor Appl Climatol 114(12):139-152

Martínez MD, Lana X, Burgueño A, Serra C (2007) Spatial and temporal daily rainfall regime in Catalonia (NE Spain) derived from tour precipitation indices, years 1950-2000. Int J Climatol 27(1):123-138

Marzban C, Sandgathe S (2006) Cluster analysis for verification of precipitation fields. Weather Forecast 21(5): $824-838$

McCabe GJ, Palecki MA, Betancourt JL (2004) Pacific and Atlantic Ocean influences on multi-decadal drought frequency in the United States. Proc Natl Acad Sci U S A 101(12):4136-4141

Miller JA, Goodrich GB (2007) Regionalization and trends in winter precipitation in the northwestern USA. Clim Res 33:215-227

Modarres R, Sarhadi A (2009) Rainfall trends analysis of Iran in the last half of the twentieth century. J Geophys Res 114:D03. doi:10.1029/2008JD010707

Monahan AH (2000) Nonlinear principal component analysis by neural networks: theory and application to the Lorenz system. J Clim 13:821-835

Mourato S, Moreira M, Corte-Real J (2010) Interannual variability of precipitation distribution patterns in Southern Portugal. Int J Climatol 30(12):1784-1794

Muñoz-Díaz D, Rodrigo FS (2004) Spatio-temporal patterns of seasonal rainfall in Spain (1912-2000) using cluster and principal component analysis: comparison. Ann Geophys 22:1435-1448

Nazaripour H, Mansouri Daneshvar MR (2014) Spatial contribution of one-day precipitations variability to rainy days and rainfall amounts in Iran. Int J Environ Sci Technol 11(6):1751-1758

Paschalidou AK, Kassomenos PA, Bartzokas A (2009) A comparative study on various statistical techniques predicting ozone concentrations: implications to environmental management. Environ Monit Assess 148: $277-289$

Puvaneswaran KM, Smithson PA (1993) An objective classification of homogenous rainfall regimes in Sri Lanka. Theor Appl Climatol 48(2-3):133-145

Randall D, Wood R, Bony S, Colman R, Fichefet T, Fyfe J, Kattsov V, Pitman A, Shukla J, Srinivasan J, Stouffer R, Sumi A, Taylor K (2007) Climate models and their evaluation. In: Solomon S, Qin D, Manning M, Chen Z, Marquis M, Averyt K, Tignor M, Miller H (eds) Climate change 2007: the physical science basis. Contribution of Working Group I to the Fourth Assessment Report of the Intergovernmental Panel on Climate Change. Cambridge University Press, Cambridge 
Raziei T, Bordi I, Pereira LS (2008) A precipitation-based regionalization for Western Iran and regional drought variability. Hydrol Earth Syst Sci 12:1309-1321

Raziei T, Mofidi A, Santos JA, Bordi B (2012) Spatial patterns and regimes of daily precipitation in Iran in relation to large-scale atmospheric circulation. Int J Climatol 32(8):1226-1237

Raziei T, Daryabari J, Bordi I, Pereira LS (2014) Spatial patterns and temporal trends of precipitation in Iran. Theor Appl Climatol 115(3-4):531-540

Rodrigo FS, Trigo RM (2007) Trends in daily rainfall in the Iberian Peninsula from 1951 to 2002. Int J Climatol 27(4):513-529

Senapathi D, Underwood F, Black E, Nicoll MAC, Norris K (2010) Evidence for long-term regional changes in precipitation on the East Coast Mountains in Mauritius. Int J Climatol 30(8):1164-1177

Shukla S, Mostaghimi S, Al-Smadi M (2000) Multivariate technique for base flow separation using water quality data. J Hydrol Eng 5(2):172-179

Soltani S, Modarres R, Eslamian SS (2007) The use of time series modeling for the determination of rainfall climates of Iran. Int J Climatol 27(6):819-829

Soltani S, Saboohi R, Yaghmaei L (2012) Rainfall and rainy days trend in Iran. Clim Chang 110(1-2):187-213

Storch HV, Zwiers FW (1999) Statistical analysis in climate research. Cambridge University Press, Cambridge, p $494 \mathrm{pp}$

Tabari H, Hosseinzadeh Talaee P (2011) Temporal variability of precipitation over Iran: 1966-2005. J Hydrol 396(3-4):313-320

White D, Richman M, Yarnal B (1991) Climate regionalization and rotation of principal components. Int J Climatol 11(1):1-25

Wilks DS (1995) Statistical methods in the atmospheric sciences, An introduction. International Geophysics Series 59, San Diego, p 467

Xiao M, Zhang Q, Singh VP, Chen X (2013) Regionalization-based spatiotemporal variations of precipitation regimes across China. Theor Appl Climatol 114(1-2):203-212

Yatagai A, Arakawa O, Kamiguchi K, Kawamoto H, Nodzu MI, Hamada A (2009) A 44-year daily gridded precipitation dataset for Asia based on a dense network of rain gauges. SOLA 5:137-140

Yatagai A, Kamiguchi K, Arakawa O, Hamada A, Yasutomi N, Kitoh A (2012) APHRODITE: constructing a long-term daily gridded precipitation dataset for Asia based on a dense network of rain gauges. Bull Am Meteorol Soc 93(9):1401-1415

Yu Z-P, Chu P-S, Schroeder T (1997) Predictive skills of seasonal to annual rainfall variations in the U.S. Affiliated Pacific Islands: canonical correlation analysis and multivariate principal component regression approaches. J Clim 10:2586-2599 